\title{
Ankle-brachial index and eicosapentaenoic acid/arachidonic acid ratio in smokers with type 2 diabetes mellitus
}

Kenta Okada ${ }^{1,2^{*}}$, Kazuhiko Kotani ${ }^{3}$ and Shun Ishibashi ${ }^{1}$

\begin{abstract}
Background: The ankle-brachial index (ABI) is an indicator of peripheral arterial damage and a low $(A B I \leq 1.0)$ or borderline $(A B \mid=1.00-1.09)$ value is associated with risk of cardiovascular disease events. A low ratio of serum eicosapentaenoic acid to arachidonic acid (EPA/AA) is also a risk factor for cardiovascular disease events. This study examined associations between the ABI and the EPA/AA ratio in smokers and non-smokers with type 2 diabetes mellitus (T2DM).

Findings: Blood data including EPA, AA, and ABI were measured in smokers and non-smokers with T2DM enrolled at Jichi Medical University ( $n=116$, male $86 \%$, mean age $59 \mathrm{yr}$ ). The patients were classified into two groups according to their ABI level: $<1.1$ (low to borderline) or $\geq 1.1$ (high). The EPAAA ratio in smoking patients with $\mathrm{ABI}<1.1$ ( $n=26$; EPA $A A=0.25)$ was significantly lower than in those with $A B I \geq 1.1(n=32$; EPA $A A=0.34 ; p=0.03)$, but was not significantly different in non-smoking patients. The EPA/AA ratio was independently, significantly, and positively correlated with the ABl level $(\beta=0.41 ; p<0.01)$ after adjusting for multiple variables only in smoking patients with T2DM.
\end{abstract}

Conclusions: The EPA/AA ratio may be associated with subclinical peripheral arterial damage in smokers with T2DM. Further studies are warranted.

Keywords: Arachidonic acid, Eicosapentaenoic acid, Peripheral arterial disease, Smoking

\section{Findings}

\section{Background}

Smokers have an increased risk of peripheral arterial damage, which is associated with cardiovascular disease (CVD) events in patients with diabetes mellitus (DM) [1]. Multifaceted studies of subclinical peripheral arterial damage are thus important for prevention of CVD in patients with DM. Assessment of peripheral arterial damage is often conducted noninvasively using the ankle-brachial index (ABI) $[2,3]$. Although $A B I<0.9$ has diagnostic value for peripheral arterial disease (PAD) [2, 3], a low-to-borderline level of $\mathrm{ABI}(0.9-1.1)$ is also associated with increased risk of CVD events and related mortality $[4,5]$.

\footnotetext{
* Correspondence: kokada@jichi.ac.jp

${ }^{1}$ Division of Endocrinology and Metabolism, Department of Internal

Medicine, Jichi Medical University, 3311-1 Yakushiji, Shimotsuke-City, Tochig

329-0498, Japan

${ }^{2}$ Nasu Chuoh Hospital, 1453 Shimoishigami, Otawara-City, Tochigi 329-0436, Japan

Full list of author information is available at the end of the article
}

A low ratio of serum eicosapentaenoic acid to arachidonic acid (EPA/AA) has also been correlated with CVD events in patients with DM [6, 7]. An additional study reported that the EPA/AA ratio was positively associated with the ABI level in hospitalized patients, although it did not take into account smoking habits or DM pathology [8]. Recently, we reported that a low EPA/AA ratio is often seen in elderly patients with type $2 \mathrm{DM}$ (T2DM), particularly in smokers [9]. However, the association between the ABI and EPA/AA ratio has not been elucidated; therefore, in the present study, we aimed to investigate the correlation between $\mathrm{ABI}$ and EPA/AA among smokers with T2DM.

\section{Subjects and methods Study participants}

A cross-sectional study of 116 smoking and non-smoking T2DM patients (2 groups of 50 men and 8 women, mean age $59 \mathrm{yr}$ in each group) who visited the Jichi Medical University Hospital, Shimotsuke, Japan for more 1 yr was 
conducted from April to September 2014. Smoking habits were confirmed via self-reports. Current smoking status was designated as either smoking or not smoking. None of the patients were taking medications containing EPA or AA. We excluded patients with a history of CVD events, recent acute illness, systemic inflammatory disease, severe nephropathy (i.e., stage 3-5), liver dysfunction, type 1 $\mathrm{DM}$, and PAD. The study was approved by the Jichi Medical University Ethical Committee and informed consent was obtained from all patients.

Hypertension was defined as systolic blood pressure $(\mathrm{SBP}) \geq 140 \mathrm{~mm} \mathrm{Hg}$, diastolic blood pressure $\geq 90 \mathrm{~mm} \mathrm{Hg}$, and/or anti-hypertensive drug use [10]. Nephropathy was defined as a urinary albumin-to-creatinine ratio $>30 \mathrm{mg} / \mathrm{g}$ creatinine, above the micro albuminuria level [11].

\section{Data collection}

Fasting blood samples were collected at the outpatient clinic to measure levels of glucose, hemoglobin A1c (HbA1c), total cholesterol, triglycerides, high-density lipoprotein cholesterol, EPA, and AA. A high-performance liquid chromatography system (HLA-723G8; Tosoh Corp., Tokyo, Japan) was used to measure HbA1c. Serum lipids were extracted by Folch's method and the fatty acids (internal standard, tricosanoic acid [C23:0]) were methylated with boron trifluoride and methanol. EPA and AA levels in the methylated fatty acids were then analyzed by gas chromatography (GC-2010; Shimadzu Corp., Kyoto, Japan) with a capillary column (TC-70; GL Sciences Inc., Tokyo, Japan).

The ABI was determined using a pulse pressure analyzer (model BP-203RPEIII; Omron Colin Corp., Tokyo, Japan) as previously described [12]. ABI was determined based on the SBP in both the upper (brachial arterial) and lower (tibial arterial) arteries [13] and was calculated by dividing the ankle SBP by the brachial SBP. The patient population was divided into two ABI groups $(<1.1$ and $\geq 1.1)$ based on previous studies $[4,14]$.

\section{Statistical analysis}

Smoking and non-smoking patients were matched for age and sex. Comparisons between smoking and nonsmoking groups were conducted using an unpaired $t$-test or chi-square test. Differences in parameters between $\mathrm{ABI}$ groups were analyzed using an unpaired $t$-test or chi-square test. Correlations between absolute ABI and the other parameters (including the EPA/AA ratio) were examined using a Pearson's correlation test and stepwise multiple regression analysis (SPSS software; SPSS Inc., IL, USA). All parameters were included in the stepwise multiple regression model except for the EPA, which was not included due to multicollinearity with the EPA/ $\mathrm{AA}$ ratio and the stronger correlation of the EPA/AA ratio with the ABI. Parameters with skewed distributions were log-transformed prior to all analyses. A $p$-value of $<0.05$ was considered to be significant.

\section{Results}

Clinical characteristics of the study population for the smoking and non-smoking groups are shown in Table 1. The HbA1c level and percentage with neuropathy complications were higher in the smoking group than in the non-smoking group.

Two patients with $\mathrm{ABI}<0.9$ (the defined PAD level) were included in the smoking group. In the smoking group, patients with $\mathrm{ABI}<1.1$ had significantly lower $\mathrm{EPA} / \mathrm{AA}$ ratios than did those with $\mathrm{ABI} \geq 1.1$, while the $\mathrm{AA}$ and EPA alone did not show clear differences between patients with $\mathrm{ABI}<1.1$ and $\geq 1.1$. The other parameters were not statistically different between the groups (Table 2). In contrast, patients with $\mathrm{ABI} \leq 1.1$ had a significantly higher $\mathrm{HbA} 1 \mathrm{c}$ than did those with $\mathrm{ABI} \geq 1.1$ in the

Table 1 Clinical characteristics of the study population by current smoking habit

\begin{tabular}{|c|c|c|c|}
\hline Parameter & Non-smoker $(n=58)$ & Smoker $(n=58)$ & $p$ \\
\hline Age, yr & $59 \pm 12$ & $59 \pm 10$ & 0.91 \\
\hline Sex, male (\%) & $50(86 \%)$ & $50(86 \%)$ & 1.00 \\
\hline $\begin{array}{l}\text { Body mass index, } \\
\mathrm{kg} / \mathrm{m}^{2}\end{array}$ & $26.3 \pm 4.4$ & $26.2 \pm 4.5$ & 0.88 \\
\hline $\begin{array}{l}\text { Systolic blood pressure, } \\
\mathrm{mm} \mathrm{Hg}\end{array}$ & $131 \pm 14$ & $131 \pm 11$ & 0.80 \\
\hline $\begin{array}{l}\text { Diastolic blood pressure, } \\
\mathrm{mm} \mathrm{Hg}\end{array}$ & $77 \pm 11$ & $79 \pm 10$ & 0.43 \\
\hline $\begin{array}{l}\text { Antihypertensive drugs, } \\
n(\%)\end{array}$ & $33(57 \%)$ & $43(74 \%)$ & 0.05 \\
\hline Glucose, mg/dL & $149 \pm 62$ & $139 \pm 42$ & 0.29 \\
\hline Hemoglobin A1c, \% & $7.2 \pm 1.0$ & $7.6 \pm 1.0$ & $0.045^{*}$ \\
\hline Insulin injection, $n$ (\%) & $15(26 \%)$ & $14(24 \%)$ & 0.83 \\
\hline Retinopathy, n (\%) & $18(31 \%)$ & $23(40 \%)$ & 0.33 \\
\hline Neuropathy, n (\%) & $24(41 \%)$ & $36(62 \%)$ & $0.03^{*}$ \\
\hline Nephropathy, n (\%) & $19(33 \%)$ & $25(43 \%)$ & 0.25 \\
\hline $\begin{array}{l}\text { LDL cholesterol, } \\
\mathrm{mg} / \mathrm{dL}\end{array}$ & $97 \pm 31$ & $95 \pm 33$ & 0.73 \\
\hline $\begin{array}{l}\text { HDL cholesterol, } \\
\mathrm{mg} / \mathrm{dL}\end{array}$ & $60 \pm 17$ & $55 \pm 16$ & 0.13 \\
\hline Triglycerides, mg/dL & $114(73-160)$ & $125(91-173)$ & 0.19 \\
\hline Statin drugs, $n(\%)$ & $21(36 \%)$ & $22(38 \%)$ & 0.85 \\
\hline $\mathrm{AA}, \mu \mathrm{g} / \mathrm{mL}$ & $173(151-212)$ & $181(152-234)$ & 0.49 \\
\hline $\mathrm{EPA}, \mu \mathrm{g} / \mathrm{mL}$ & 60 (41-96) & $52(36-86)$ & 0.28 \\
\hline EPA/AA ratio & $0.37(0.23-0.56)$ & $0.29(0.19-0.42)$ & 0.08 \\
\hline Ankle-brachial index & $1.14 \pm 0.07$ & $1.11 \pm 0.09$ & 0.07 \\
\hline
\end{tabular}

Data are means \pm standard deviations, medians (interquartile ranges), or numbers (\%)

$L D L$ low-density lipoprotein, $H D L$ high-density lipoprotein, $A A$ arachidonic acid, EPA eicosapentaenoic acid

* $p<0.05$ for comparison between groups by smoking ( $t$-test or chi-square test) 
Table 2 Clinical characteristics of the study population by $A B I(<1.1$ and $\geq 1.1)$

\begin{tabular}{|c|c|c|c|c|c|c|}
\hline \multirow[b]{2}{*}{ Parameter } & \multicolumn{2}{|l|}{ Non-smoker } & \multirow[t]{2}{*}{$p$} & \multicolumn{2}{|l|}{ Smoker } & \multirow[t]{2}{*}{$p$} \\
\hline & $\mathrm{ABI}<1.1(n=17)$ & $\mathrm{ABI} \geq 1.1(n=41)$ & & $\mathrm{ABI}<1.1(n=26)$ & $\mathrm{ABI} \geq 1.1(n=32)$ & \\
\hline Age, yr & $56 \pm 14$ & $60 \pm 11$ & 0.21 & $58 \pm 10$ & $60 \pm 11$ & 0.61 \\
\hline Sex, male (\%) & $15(88 \%)$ & 35 (85 \%) & 0.77 & $22(85 \%)$ & $28(88 \%)$ & 0.75 \\
\hline Body mass index, $\mathrm{kg} / \mathrm{m}^{2}$ & $26.5 \pm 5.6$ & $26.2 \pm 3.9$ & 0.77 & $25.5 \pm 3.8$ & $26.7 \pm 5.0$ & 0.31 \\
\hline $\begin{array}{l}\text { Systolic blood pressure, } \\
\mathrm{mm} \mathrm{Hg}\end{array}$ & $133 \pm 17$ & $130 \pm 13$ & 0.45 & $131 \pm 10$ & $132 \pm 12$ & 0.77 \\
\hline $\begin{array}{l}\text { Diastolic blood pressure, } \\
\mathrm{mm} \mathrm{Hg}\end{array}$ & $80 \pm 13$ & $76 \pm 10$ & 0.22 & $79 \pm 9$ & $78 \pm 10$ & 0.76 \\
\hline Antihypertensive drugs, $n$ (\%) & $12(71 \%)$ & $21(51 \%)$ & 0.18 & 20 (77 \%) & $23(72 \%)$ & 0.66 \\
\hline Glucose, mg/dL & $157 \pm 39$ & $146 \pm 70$ & 0.55 & $137 \pm 42$ & $140 \pm 43$ & 0.74 \\
\hline Hemoglobin A1c, \% & $7.7 \pm 1.2$ & $7.0 \pm 0.8$ & $0.01^{*}$ & $7.6 \pm 1.0$ & $7.5 \pm 1.0$ & 0.82 \\
\hline Insulin injection, $n$ (\%) & $7(41 \%)$ & $8(20 \%)$ & 0.09 & $3(12 \%)$ & 11 (34 \%) & 0.06 \\
\hline Retinopathy, n (\%) & $6(35 \%)$ & $12(29 \%)$ & 0.65 & $9(35 \%)$ & $14(44 \%)$ & 0.48 \\
\hline Neuropathy, n (\%) & $10(59 \%)$ & $14(34 \%)$ & 0.08 & $10(38 \%)$ & 15 (47 \%) & 0.52 \\
\hline Nephropathy, n (\%) & $5(29 \%)$ & $14(34 \%)$ & 0.73 & 16 (62 \%) & 20 (63\%) & 0.94 \\
\hline LDL cholesterol, mg/dL & $96 \pm 38$ & $97 \pm 28$ & 0.88 & $95 \pm 39$ & $94 \pm 28$ & 0.95 \\
\hline HDL cholesterol, mg/dL & $61 \pm 18$ & $59 \pm 16$ & 0.68 & $52 \pm 14$ & $57 \pm 18$ & 0.23 \\
\hline Triglycerides, mg/dL & $127(79-217)$ & $107(69-144)$ & 0.18 & 139 (116-233) & $118(83-159)$ & 0.09 \\
\hline Statin drugs, $n(\%)$ & $6(35 \%)$ & $15(37 \%)$ & 0.93 & $13(50 \%)$ & $9(28 \%)$ & 0.09 \\
\hline $\mathrm{AA}, \mu \mathrm{g} / \mathrm{mL}$ & $176(144-214)$ & $173(150-210)$ & 0.51 & $191(158-244)$ & $180(134-227)$ & 0.18 \\
\hline $\mathrm{EPA}, \mu \mathrm{g} / \mathrm{mL}$ & $64(46-114)$ & $60(41-97)$ & 0.26 & $49(33-69)$ & $68(41-96)$ & 0.07 \\
\hline EPA/AA ratio & $0.44(0.21-0.75)$ & $0.37(0.23-0.55)$ & 0.56 & $0.25(0.16-0.40)$ & $0.34(0.20-0.69)$ & $0.03^{*}$ \\
\hline Ankle-brachial index & $1.06 \pm 0.04$ & $1.17 \pm 0.05$ & $<0.01^{* *}$ & $1.03 \pm 0.06$ & $1.18 \pm 0.05$ & $<0.01^{* *}$ \\
\hline
\end{tabular}

Data are means \pm standard deviations, medians (interquartile ranges), or numbers (\%)

$L D L$ low-density lipoprotein, $H D L$ high-density lipoprotein, $A A$ arachidonic acid, EPA eicosapentaenoic acid

${ }^{*} p<0.05,{ }^{* *} p<0.01$ for comparison between ABI groups ( $t$-test or chi-square test)

non-smoking group. There were no statistical differences in the other parameters, including EPA/AA, with ABI levels in the non-smoking group.

Correlations of absolute ABI with the other parameters are listed in Table 3. Pearson's correlation tests found that EPA and the EPA/AA ratio were significantly and positively correlated with $A B I$ levels in the smoking group, while HbA1c was significantly and negatively correlated with ABI levels in the non-smoking group. Stepwise multiple regression analysis revealed that the EPA/ AA ratio was independently, significantly, and positively correlated with $\mathrm{ABI}$ levels and that use of statin drugs was inversely correlated with $\mathrm{ABI}$ levels in the smoking group, while HbA1c was independently, significantly, and negatively correlated with ABI levels in the nonsmoking group.

\section{Discussion}

We found that the EPA/AA ratio was lower in patients with $\mathrm{ABI}<1.1$ than in those with $\mathrm{ABI} \geq 1.1$, with a positive correlation between the EPA/AA ratio and $\mathrm{ABI}$ in smokers with T2DM. To our knowledge, a relationship between the EPA/AA ratio and ABI level among smokers or non-smokers with T2DM has not previously been reported. Accordingly, the results of this study suggest that the EPA/AA ratio may be associated with subclinical PAD in smokers with T2DM.

By contrast of $n-3$ fatty acids, particularly EPA, $n-6$ fatty acids, particularly AA, impair peripheral arteries by creating vasoactive oxygen radicals and promoting cyclooxygenase metabolism $[15,16]$. In smokers, a delayed conversion of AA to eicosanoids is known [17-19], this may result in endothelial dysfunction in peripheral arteries [20]. This is a possible mechanism for a positive correlation between the EPA/AA ratio and ABI levels in smokers with $\mathrm{DM}$, although this requires further research.

Based on the results of our stepwise regression model, ABI was inversely associated with the use of statin drugs in the smoking group. Statins are often prescribed for patients with DM, particularly when the patients may have complications of DM. As a result, patients with subclinical PAD may use statins. This is only a hypothesis; however, similar results were reported in a previous study [21]. 
Table 3 Correlations between the absolute value of the ankle-brachial index and other parameters

\begin{tabular}{|c|c|c|c|c|}
\hline \multirow[b]{2}{*}{ Parameter } & \multicolumn{2}{|l|}{ Non-smoker } & \multicolumn{2}{|l|}{ Smoker } \\
\hline & $r(p)$ & $\beta(p)$ & $r(p)$ & $\beta(p)$ \\
\hline Age, yr & $0.23(0.09)$ & $\mathrm{NE}$ & $0.06(0.67)$ & $\mathrm{NE}$ \\
\hline Sex, male (\%) & $0.14(0.31)$ & $0.19(0.12)$ & $0.03(0.81)$ & $\mathrm{NE}$ \\
\hline Body mass index, $\mathrm{kg} / \mathrm{m}^{2}$ & $0.07(0.61)$ & NE & $0.05(0.70)$ & NE \\
\hline Systolic blood pressure, mm Hg & $0.05(0.71)$ & $\mathrm{NE}$ & $0.04(0.78)$ & $\mathrm{NE}$ \\
\hline Diastolic blood pressure, $\mathrm{mm} \mathrm{Hg}$ & $0.11(0.41)$ & $\mathrm{NE}$ & $0.13(0.35)$ & $\mathrm{NE}$ \\
\hline Antihypertensive drugs, $n$ (\%) & $0.15(0.27)$ & $\mathrm{NE}$ & $0.10(0.45)$ & $\mathrm{NE}$ \\
\hline Glucose, mg/dL & $0.16(0.25)$ & $\mathrm{NE}$ & $0.03(0.85)$ & $\mathrm{NE}$ \\
\hline Hemoglobin A1c, (\%) & $0.46\left(<0.01^{* *}\right)$ & $0.45\left(<0.01^{* *}\right)$ & $0.01(0.95)$ & $\mathrm{NE}$ \\
\hline Insulin injection, $n(\%)$ & $0.21(0.12)$ & $\mathrm{NE}$ & $0.19(0.14)$ & $0.26(0.06)$ \\
\hline Retinopathy, n (\%) & $0.02(0.91)$ & $\mathrm{NE}$ & $0.08(0.54)$ & $\mathrm{NE}$ \\
\hline Neuropathy, n (\%) & $0.18(0.18)$ & $\mathrm{NE}$ & $0.04(0.79)$ & $\mathrm{NE}$ \\
\hline Nephropathy, n (\%) & $0.08(0.58)$ & $\mathrm{NE}$ & $0.05(0.73)$ & $\mathrm{NE}$ \\
\hline LDL cholesterol, mg/dL & $0.01(0.95)$ & $\mathrm{NE}$ & $0.05(0.72)$ & $\mathrm{NE}$ \\
\hline HDL cholesterol, mg/dL & $0.06(0.67)$ & $\mathrm{NE}$ & $0.22(0.10)$ & $\mathrm{NE}$ \\
\hline Triglycerides, mg/dL & $0.22(0.11)$ & $0.16(0.17)$ & $0.16(0.27)$ & $\mathrm{NE}$ \\
\hline Statin drugs, $n$ (\%) & $0.12(0.37)$ & $\mathrm{NE}$ & $0.15(0.26)$ & $0.31\left(0.03^{*}\right)$ \\
\hline $\mathrm{AA}, \mu \mathrm{g} / \mathrm{mL}$ & $0.04(0.78)$ & - & $0.13(0.32)$ & - \\
\hline $\mathrm{EPA}, \mu \mathrm{g} / \mathrm{mL}$ & $0.19(0.16)$ & - & $0.28\left(0.04^{*}\right)$ & - \\
\hline EPA/AA ratio & $0.05(0.73)$ & $\mathrm{NE}$ & $0.31\left(0.02^{*}\right)$ & $0.41\left(<0.01^{* *}\right)$ \\
\hline
\end{tabular}

$L D L$ low-density lipoprotein, $H D L$ high-density lipoprotein, $A A$ arachidonic acid, $E P A$ eicosapentaenoic acid, $N E$ not extracted; -: not used in the analysis. Data are Pearson's $r$ correlation coefficients and standardized $\beta$ coefficients from stepwise multiple regression analysis ${ }^{*} p<0.05,{ }^{* *} p<0.01$

The present study had certain limitations. It was a cross-sectional study with a small sample size; thus, further intervention and a placebo control study are needed. Additionally, as there was no information regarding dietary fish consumption, smoking dose, or smoking duration (e.g., the Brinkman index), and because the cigarette type was not investigated in detail, these factors could not be considered in our analysis.

\section{Conclusions}

In summary, the EPA/AA ratio may be associated with subclinical PAD in smokers with T2DM. The utility of measuring the EPA/AA ratio along with $\mathrm{ABI}$ should be further investigated in future studies.

\section{Abbreviations}

AA: arachidonic acid; ABI: ankle-brachial index; CVD: cardiovascular disease; DM: diabetes mellitus; EPA: eicosapentaenoic acid; HbA1c: hemoglobin A1c; PAD: peripheral arterial disease; SBP: systolic blood pressure; T2DM: type 2 diabetes mellitus.

\section{Competing interests}

The authors declare that they have no conflicts of interest.

\section{Authors' contributions}

$\mathrm{KO}$ researched the data, wrote the manuscript, and contributed to the discussion; KK analyzed the data and edited and reviewed the manuscript; and SI contributed to the discussion and reviewed the manuscript. All authors read and approved the final manuscript.

\section{Acknowledgments}

No funding was received for this study.

\section{Author details}

'Division of Endocrinology and Metabolism, Department of Internal Medicine, Jichi Medical University, 3311-1 Yakushiji, Shimotsuke-City, Tochigi 329-0498, Japan. ${ }^{2}$ Nasu Chuoh Hospital, 1453 Shimoishigami, Otawara-City, Tochigi 329-0436, Japan. ${ }^{3}$ Division of Community and Family Medicine, Jichi Medical University, 3311-1 Yakushiji, Shimotsuke-City, Tochigi 329-0498, Japan.

Received: 1 November 2014 Accepted: 25 January 2016

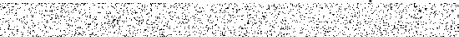

\section{References}

1. Althouse AD, Abbott JD, Forker AD, Bertolet M, Barinas-Mitchell E, Thurston $\mathrm{RC}$, et al. Risk factors for incident peripheral arterial disease in type 2 diabetes: results from the Bypass Angioplasty Revascularization Investigation in type 2 Diabetes (BARI 2D) Trial. Diabetes Care. 2014;37(5):1346-52.

2. Yao ST, Hobbs JT, Irvine WT. Ankle systolic pressure measurements in arterial disease affecting the lower extremities. Br J Surg. 1969;56(9):676-9.

3. Ouriel K, Zarins CK. Doppler ankle pressure: an evaluation of three methods of expression. Arch Surg. 1982;117(10):1297-300.

4. Diehm C, Lange S, Darius H, Pittrow D, von Stritzky B, Tepohl G, et al. Association of low ankle brachial index with high mortality in primary care. Eur Heart J. 2006;27(14):1743-9.

5. Kato A, Takita T, Furuhashi M, Kumagai $H$, Hishida A. A small reduction in the ankle-brachial index is associated with increased mortality in patients on chronic hemodialysis. Nephron Clin Pract. 2010;114(1):c29-37. 
6. Matsuzaki M, Yokoyama M, Saito Y, Origasa H, Ishikawa Y, Oikawa S, et al. Incremental effects of eicosapentaenoic acid on cardiovascular events in statintreated patients with coronary artery disease. Circ J. 2009;73(7):1283-90.

7. Domei T, Yokoi H, Kuramitsu S, Soga Y, Arita T, Ando K, et al. Ratio of serum $n-3$ to $n-6$ polyunsaturated fatty acids and the incidence of major adverse cardiac events in patients undergoing percutaneous coronary intervention. Circ J. 2012;76(2):423-9.

8. Fujihara M, Fukata M, Odashiro K, Maruyama T, Akashi K, Yokoi Y. Reduced plasma eicosapentaenoic acid-arachidonic acid ratio in peripheral artery disease. Angiology. 2013;64(2):112-8.

9. Okada K, Kotani K, Yagyu H, Ishibashi S. Eicosapentaenoic acid/arachidonic acid ratio and smoking status in elderly patients with type 2 diabetes mellitus. Diabetol Metab Syndr. 2014;6(1):85.

10. Pickering TG, Hall JE, Appel $\amalg$, Falkner BE, Graves J, Hill MN, et al. Recommendations for blood pressure measurement in humans and experimental animals: Part 1: blood pressure measurement in humans: a statement for professionals from the Subcommittee of Professional and Public Education of the American Heart Association Council on High Blood Pressure Research. Hypertension. 2005;45(1):142-61.

11. Levey AS, de Jong PE, Coresh J, El Nahas M, Astor BC, Matsushita K, et al. The definition, classification, and prognosis of chronic kidney disease: a KDIGO Controversies Conference report. Kidney Int. 2011;80(1):17-28.

12. Yamashina A, Tomiyama H, Takeda K, Tsuda H, Arai T, Hirose K, et al. Validity, reproducibility, and clinical significance of noninvasive brachial-ankle pulse wave velocity measurement. Hypertens Res. 2002;25(3):359-64.

13. Price JF, Tzoulaki I, Lee AJ, Fowkes FG. Ankle brachial index and intima media thickness predict cardiovascular events similarly and increased prediction when combined. J Clin Epidemiol. 2007;60(10):1067-75.

14. Jin X, Ma JH, Shen Y, Luo Y, Su XF, Chen YY, et al. An analysis of the relationship between ankle-brachial index and estimated glomerular filtration rate in type 2 diabetes. Angiology. 2012;64(3):237-41.

15. Ellis EF, Police RJ, Dodson LY, McKinney JS, Holt SA. Effect of dietary n-3 fatty acids on cerebral microcirculation. Am J Physiol. 1992;262(5 Pt 2): H1379-86.

16. Shishehbor MH, Zhang R, Medina H, Brennan ML, Brennan DM, Ellis SG, et al. Systemic elevations of free radical oxidation products of arachidonic acid are associated with angiographic evidence of coronary artery disease. Free Radic Biol Med. 2006;41(11):1678-83.

17. Sinzinger $\mathrm{H}$, Kaliman J, Oguogho A. Eicosanoid production and lymphatic responsiveness in human cigarette smokers compared with non-smokers. Lymphology. 2000;33(1):24-31.

18. Pawlosky RJ, Hibbeln JR, Salem Jr N. Compartmental analyses of plasma n-3 essential fatty acids among male and female smokers and nonsmokers. J Lipid Res. 2007;48(4):935-43.

19. Simon JA, Fong J, Bernert Jr JT, Browner WS. Relation of smoking and alcohol consumption to serum fatty acids. Am J Epidemiol. 1996;144(4):325-34.

20. Saravanan P, Davidson NC, Schmidt EB, Calder PC. Cardiovascular effects of marine omega-3 fatty acids. Lancet. 2010;376(9740):540-50

21. Nozue T, Yamamoto S, Tohyama S, Fukui K, Umezawa S, Onishi Y, et al. Effects of serum n-3 to n-6 polyunsaturated fatty acids ratios on coronary atherosclerosis in statin-treated patients with coronary artery disease. Am J Cardiol. 2013;111(1):6-11.

\section{Submit your next manuscript to BioMed Central and we will help you at every step:}

- We accept pre-submission inquiries

- Our selector tool helps you to find the most relevant journal

- We provide round the clock customer support

- Convenient online submission

- Thorough peer review

- Inclusion in PubMed and all major indexing services

- Maximum visibility for your research

Submit your manuscript at www.biomedcentral.com/submit

) Biomed Central 